\title{
Factors Influencing the Determination of the Gyrosures Potential of Small Rivers
}

\author{
Alifbek Kirgizov, Sherkhon Sultonov", Khislatbek Usmonov and Mirzosharif Rajabov \\ Tajik Technical University named after M.S. Osimi, Dushanbe, Tajikistan
}

\begin{abstract}
The article examines the main trends in the use of renewable energy sources in the world. The article examines the main trends in the use of renewable energy sources in the world. The use of renewable sources is associated with the depletion of reserves of carbonaceous minerals and a decrease in greenhouse gas emissions into the atmosphere. The article presents the main, according to the authors, reasons for the incorrect determination of the potential of small hydro resources in the Republic of Tajikistan. In recent years, many small hydroelectric power plants have been built, which are ineffective. For this, the authors propose a more detailed study of the watercourse regime and the determination of its potential for the minimum and maximum tributaries and the possibility of its use, the influence of hydrological, socio-economic factors on the determination of the potential of small rivers during the construction of small hydroelectric power plants. Zoning of small watercourses is proposed for a more detailed determination of the watercourse capacity and the possibility of constructing small hydroelectric power stations on them. The influence of altitude above sea level on the output of the rated power of installations of renewable energy sources is considered. As it shows, the experience of operation and the above statistical analysis at the existing small hydroelectric power plants with an altitude of SHPPs above sea level, their nominal capacity will decrease. The decrease in the nominal output power of small hydroelectric power plants with an air-cooling system is associated with the rarefaction of atmospheric air.
\end{abstract}

\section{Introduction}

Tajikistan, like most countries, does not have its own minerals, and all energy is generated using renewable energy sources, especially hydropower. The use of renewable energy sources has most of the unsolved problems associated with determining the potential and modes of operation of renewable energy sources depending on their geographical location. Today, there are still many unresolved problems in using renewable energy sources and a unified approach to solving all the shortcomings. The design of renewable energy installations requires both technical and economic, and social solutions. Since Tajikistan, in most of its cases, uses hydro resources, it is necessary to develop a unified approach to solving the problems of using small hydropower resources.

\footnotetext{
*Corresponding author: sultonzoda.sh@mail.ru
} 


\subsection{Design assumptions for small hydro power plants}

In this article, we will try to formulate objective obstacles that reduce the role and importance of small hydropower in the creation of decentralized power supply zones in certain hard-to-reach high-mountainous regions of Tajikistan based on the construction of small hydropower plants, in order to develop an event in subsequent chapters and propose ways and means to stimulate the use of renewable energy sources.

The main disadvantages of the design process in the field of small hydropower, which have been consistently repeated over the past 30 years of Tajikistan's independence, include the following:

- Lack of a scheme for the integrated use of water resources of the main rivers

- Lack of basin schemes for the integrated use of water resources;

- Lack of local schemes for the integrated use of water resources of individual watercourses;

- Lack of information on the resource base of small hydropower in the Republic;

- Poor hydrological knowledge of small streams;

- Lack of relevant law and clearly formulated state goals and priorities for the development of renewable resources, there are no governing bodies at regional levels and research centers;

- Low level of standardization and certification of equipment at the stage of their placement at manufacturing plants in other countries, underdeveloped infrastructure, lack of qualified service personnel, an insufficient amount of scientific, technical and technological developments, insufficient level of technical knowledge of decisionmaking organizations;

- Low public awareness of the possibilities of renewable resources, lack of widespread propaganda in the media of the possibilities and merits of these resources;

- Lack of necessary scientific and production personnel;

- Weak base of pre-design work;

- Low level of development of feasibility studies for the construction of small hydropower plants;

- Ignoring the many variations of technical solutions when choosing the main parameters of the project;

- Ignoring local conditions when choosing the main structures of the hydropower complex;

- Lack of a methodology for water and energy calculations to determine the guaranteed capacity of small HPPs;

- Ignoring climatic conditions when determining the winter mode of operation of small hydropower plants.

As you can see, a significant part of the listed problems is fundamental sections of designing hydropower facilities, including for small hydropower plants, many of which find their solutions only at the levels of state capabilities [1-3].

\section{Methods}

\subsection{Design methods for small hydropower plants}

Considering the above conditions for the development of small hydropower in the mountainous regions of Tajikistan, we consider it timely to develop practical methods for calculating the main energy indications of mini and small HPPs at the stage of feasibility study and construction. To do this, it is necessary to analyze the features of the hydrological 
regimes of small watercourses and the associated processes of freeze-up, drift and slush in these high-mountainous regions of the Republic of Tajikistan.

Geographical location also influences the determination of the potential of the river. In this case, it is necessary to have at least 10 -year data on the nature of flow changes in each section of the watercourse. In the mountainous regions of Tajikistan, the rivers mainly flow in - shaped gorges and often on $10 \mathrm{~km}$ of the river's upper floodplain. There are no elementary conditions for the construction of SHPPs. Also, such sections are usually provided with low guaranteed capacities.

On the other hand, the use of the river along its entire length is more difficult in terms of the location of settlements and avalanche danger. As practice shows, depending on the height of the location of small hydroelectric power plants (SHPP) above sea level, several problems arise that must be taken into account when designing. Since most SHPPs are built according to the watercourse regime, it is necessary to determine the operation mode of SHPPs based on their watercourse regime. Basically, the choice of SHPP capacity is based on the efficient use of water resources of the existing river. To do this, it is necessary to show the average monthly water discharge in the river in an increasing form, keeping the monthly flow in the river, Figure 1.
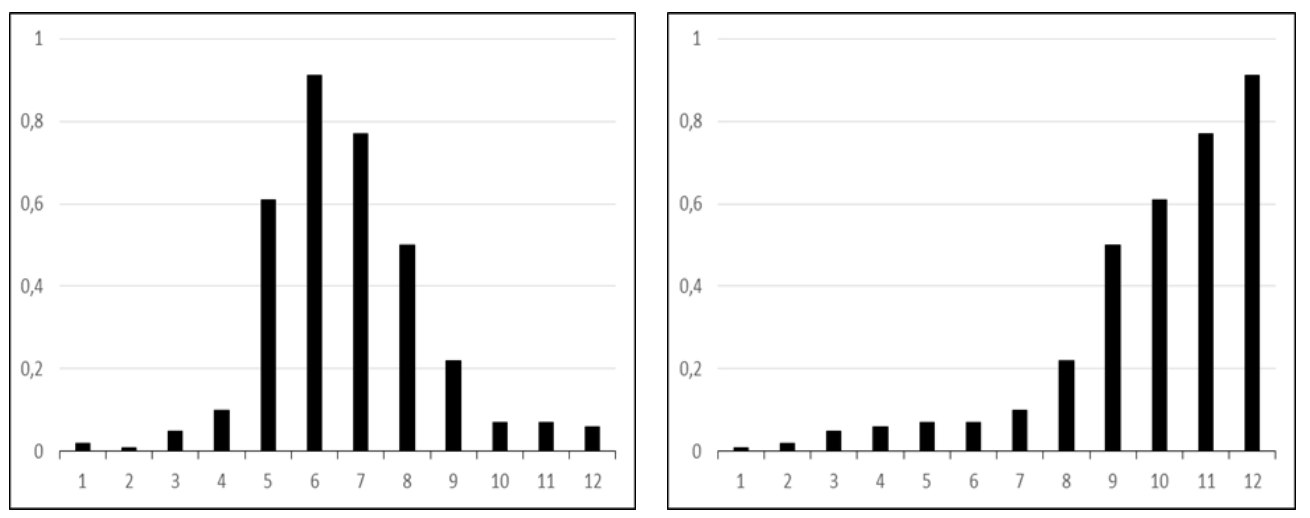

Fig. 1. Average monthly water discharge in the river

$$
q_{1}=A_{0}+A_{1} t+A_{2} t^{2}+A_{3} t^{3}, m^{3} / \mathrm{s}
$$

By determining the water consumption, you can determine the capacity of the SHPP

$$
P_{C T}=\eta g H_{p} q_{p}, k V t
$$

where $\eta$ is aggregate efficiency, $H_{p}$ is estimated consumption, $q_{p}-$ is estimated water consumption, $\mathrm{m}^{3} / \mathrm{s}$ 


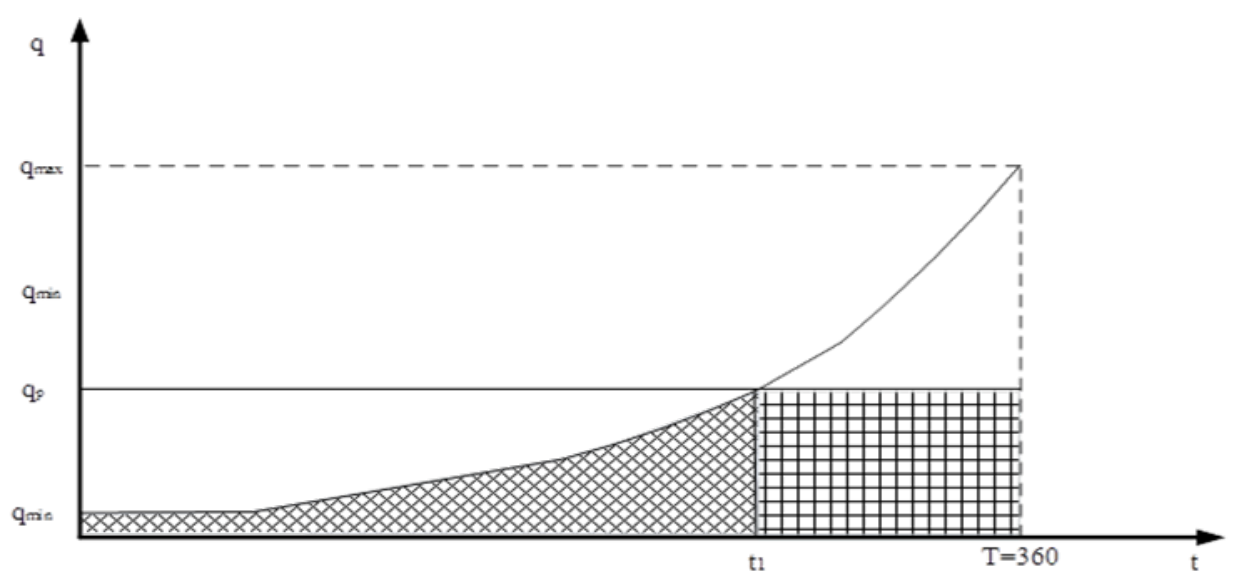

Fig. 2. Function of SHPP operation

The intersection of the straight-line function to divide the annual work schedule of the SHPP into two stages:

1. 0 - $t_{1}-$ SHPP operates on a watercourse

2. $\mathrm{t}_{1}-\mathrm{T}-\mathrm{SHPP}$ operates at rated power.

Based on the above, determine the annual flow through the SHPP by the expression:

$$
Q_{r s}=8.64 * 10^{4}\left[\int_{0}^{t_{1}} q_{t} d t+q_{p}\left(T-t_{1}\right)\right]
$$

Annual river flow

$$
Q_{r p}=8.64 * 10^{4} \int_{0}^{T} q_{t} d t, m^{3}
$$

When determining the potential of rivers, as noted above, it is necessary to divide them according to their location. The location of rivers in the regions makes it possible to more accurately determine their potential since the terrain in the regions differs significantly from each other.

To determine the hydropower potential of a watercourse using a modern methodology, it is also necessary to consider the socio-ecological characteristics of the watercourse. At the same time, environmental characteristics are of priority and limit the operation of SHPPs by the so-called "red lines" with expressions [4-8].

$$
\begin{aligned}
Z_{j i}^{\text {upper }} & =\min \left(Z_{1 i}^{\max }, Z_{2 i}^{\max }, \ldots . ., Z_{l i}^{\max }\right) \\
Z_{j i}^{\text {lower }} & =\max \left(Z_{1 i}^{\text {min }}, Z_{2 i}^{\text {min }}, \ldots \ldots, Z_{l i}^{\text {min }}\right)
\end{aligned}
$$

Based on this, electricity generation from small hydroelectric power plants, $\mathrm{kW} *$ hour 


$$
Z_{j i}^{\text {lower }}=\max \left(Z_{1 i}^{\text {min }}, Z_{2 i}^{\text {min }}, \ldots \ldots, Z_{l i}^{\text {min }}\right)
$$

where $\mathrm{H}_{\mathrm{p}}$ is measured in $\mathrm{m}$ and $\mathrm{Q}_{\mathrm{p}}-\mathrm{m}^{3}$

Taking approximately $\eta \mathrm{g}=7.5$, we get the output

$$
W_{r}=20.83 * 10^{-4} * H_{p} Q_{r s}
$$

Thus, the design capacity of a small hydroelectric power station $\mathrm{N} \mathrm{p}$ can be taken any, within the maximum to minimum average daily capacity provided by the watercourse. The option is usually guaranteed in which,

$$
N_{\text {max }}>N_{\text {guaranteed }}>N_{\text {min }}
$$

As for the second example, a small hydroelectric power plant with a daily regulation reservoir, the water-energy calculations are performed in the same way as shown above, with the only difference in the redistribution of water consumption by the useful volume of the reservoir, taking into account the coverage of the load schedule of consumers in the daily context, i.e. in 24 hours.

$$
\left.\begin{array}{c}
N_{H P P}=9.81 Q_{H P P}\left(Z_{\text {headwater }}-Z_{\text {tailwater }}-h_{\text {average }}\right) \eta_{H P P} \\
H=Z_{\text {head }}-Z_{\text {tail }}-h_{\text {aver }} \\
W_{\text {reservoir }}=\left(W_{\text {reservoirt }}-W_{\text {reservoir }}(t-1)\right) \\
Z_{\text {head }}=Z_{\text {head }}\left(W_{\text {head }}\right) \\
Z_{\text {tail }}=Z_{\text {tail }}\left(Q_{\text {tail }}\right) \\
H_{\text {aver }}=W_{\text {head }} \pm \Delta W
\end{array}\right\}
$$

where $Z_{\text {head }}, Z_{\text {tail }}$ are elevations of the head and tail of the hydroelectric power station, $\mathrm{m} ; W_{\text {rezt }}, W_{\text {rez }(t-1)}$ are reservoir volume at the moment $t$ and $(t-1), \mathrm{m}^{3} ; Q_{\text {tail }}$ is downstream discharge, $\mathrm{m}^{3} / \mathrm{s} ; t_{\text {aver }}$ is depth from the work of the reservoir, $\mathrm{m} ; t$ is time, s.

The solution to the equation system comes down to comparing water inflow with consumption and redistribution following the load schedule of electricity consumers. It should be noted that in design practice, such calculations are performed in tabular form. This method has been sufficiently developed and improved in many works by different authors and illustrated in technical literature [8-12].

The height of the small hydroelectric power station also affects the output of the rated power. As shown, the operating rate, depending on the height of the SHPP location, the output power is reduced in a linear manner shown in Table 1.

With an increase in altitude, the air becomes more rarefied, and its cooling capacity deteriorates, which will affect the generators of small hydroelectric power plants, mostly with an air-cooling system [13-20]. 
Table 1. Decrease in the capacity of SHPP depending on the height

\begin{tabular}{|c|c|c|c|c|c|c|c|c|}
\hline $\begin{array}{c}\text { Name } \\
\text { SHPP }\end{array}$ & Marzich & Somon & Vanj & Rushan & Khorog & Namadgut & Ak-Su & Bulunkul \\
\hline $\begin{array}{c}\text { SHPP } \\
\text { height } \\
\text { above } \\
\text { sea level, } \\
\text { m }\end{array}$ & 1000 & 1288 & 1815 & 1981 & 2075 & 2524 & 3576 & 3744 \\
\hline $\begin{array}{c}\text { Power in } \\
\text { \% of } \\
\text { nominal }\end{array}$ & 100 & 98 & 96 & 94 & 93 & 90 & 86 & 82 \\
\hline
\end{tabular}

\section{Conclusions}

The studies performed in this article have shown that distributed generation based on hydro resources should be selected, taking into account the output of a guaranteed power, which should be significantly overestimated from the height of the generation sources above sea level. This factor is due to the very high altitude of the geographic location of the Republic of Tajikistan, where only $7 \%$ of the territory is flat. Simultaneously, for hydroelectric power plants, there is a decrease in the nominal power due to the deterioration of the cooling conditions for generators. The seasonality of small high-mountain rivers is a dynamic system that changes in time with the total generation capacity based on hydro resources, especially considering that the absence of water accumulation in reservoirs will be insufficient.

\section{References}

1. Elistratov V.V, Breusov V.P., and Tashimbetov M.A. Renewable energy sources and methods of their use (on the example of the Central Asian region) SPb.: Publishing house "Nestor" p. 135, (2005)

2. Bukarica V., Morvaj and Robic S. United nations development program Tajikistan: Energy efficiency master plan for Tajikistan Dushanbe, p. 73, (2011)

3. Historian B.L. Research in the field of unconventional energy. Hydraulic engineering Issue 8/9, pp 81-84, (1999)

4. Manusov V.Z., Kirgizov A.K., and Sultonov Sh.M. Optimization of the Operating Mode of a Hybrid Power Complex Consisting of Renewable Energy Sources XIV International Scientific-Technical Conference on Actual Problems of Electronics Instrument Engineering (APEIE-2018) Proceedings pp.286-289, Novosibirsk Russia, (2018), IEEE Conferences DOI: 10.1109/APEIE.2018.8545665

5. Kirgizov A.K., Rasulov S.R., and Kosimov U.U. Potential of unconventional energy sources in Tajikistan Energy: Ecology, Reliability, Safety: materials of the 18th AllRussian. scientific and technical conf., Tomsk Polytechnic University. Tomsk: "SPB Graphics" pp. 99-101, (2012)

6. Osadchiy G.B., Energy sources for autonomous power supply Energetik. Issue. 4. pp. 23-25, (2002)

7. Petrov G.N. Tajikistan's Hydropower Resources. Central Asia and Caucasus Center for Social and Political Studies Sweden № 33 (21), pp. 153-161, (2003)

8. Rose A.V., Lazarev D.O., and Malyshenko S.P., Renewable energy sources. Physical 
and technical fundamentals Dolgoprudny: Intellect; M: Publishing house MPEI $\mathrm{p}$ 704, (2009)

9. Renewables Global status report. Renewable Energy Policy Network for the $21 \mathrm{st}$ Centure, Electronic resource, (2013), Access mode: www.ren21.net

10. Fortov V.E. and Popel O Energy in the modern world Publishing House "Intellect" Dolgoprudny, p.168, (2011)

11. Kirgizov A., Sultonov Sh., Johnonov M., Usmonov Kh. and Tolibzoda I. Characteristics of Relative Growth for HPP Power Systems of Tajikistan, IOP Conf. Series: Materials Science and Engineering 883, (2020) doi:10.1088/1757899X/883/1/012084

12. Kumar A., Schei T., Ahenkorah A., Caceres Rodriguez R., Devernay J-M. Freitas, M., Hall D., Killingtveit Å., Liu Z.O., Pichs-Madruga R., Sokona Y., Seyboth K., Matschoss P., Kadner S., Zwickel T., Eickemeier P., Hansen G., 'Hydropower', in Edenhofer IPCC Special Report on Renewable Energy Sources and Climate Change Mitigation. Schlömer, S. von Stechow, C. (eds.) Cambridge University Press. (2011)

13. International Energy Agency (IEA) Hydropower and the environment: Present context and guidelines for future action. Volume II: Main report. Implementing agreement for hydropower technologies and programmes, Annex III. International Energy Agency, Paris, France, p 172, (2000)

14. Immerzeel W, Van Beek, Konz L, Shresth M A,. and Bierkens M. 'Hydrological response to climate change in a glacierized catchment in the Himalayas', Climatic Change, 110, (2012)

15. Bukarica V, Morvaj S. United nations development programme Tajikistan: Energy efficiency master plan for Tajikistan Dushanbe $\mathrm{p} 73$.

16. Petrov G.N. Tajikistan's Hydropower Resources. Central Asia and Caucasus Center for Social and Political Studies. Sweden. № 33 (21), pp. 153-161, (2003)

17. Koeppel G. Reliability considerations of future energy systems Multicarrier systems and the effect of energy storage Diss. ETH No. 17058, Eidgenössische Technische Hochschule Zürich, (2007)

18. Gebretsadik Y, Fant C, Strzepek K and Arndt C. Optimized reservoir operation model of regional wind and hydro power integration case study Zambezi basin and South Africa Applied Energy, 161, pp. 574-582 (2016)

19. D. o. t. A. U.S. Planning and design of hydroelectric power plant structures C. o. E. Army, Washington, DC, (1995)

20. Doganis P, Sarimveis H, Optimization of power production through coordinated use of hydroelectric and conventional power units Applied Mathematical Modelling, 38(7-8), pp. 2051-2062, (2014) 